\title{
O relacionamento terapeuta-cliente no tratamento do transtorno obsessivo compulsivo
}

\author{
The therapist-client relationship in the treatment \\ of obsessive compulsive disorder
}

\author{
Neide Aparecida MENDES \\ LUC VANDENBERGHE ${ }^{2}$
}

\begin{abstract}
Resumo
Este artigo levanta a possibilidade de intervenção no transtorno obsessivo compulsivo por meio da psicoterapia analítica funcional. Trata-se de uma psicoterapia comportamental que se diferencia de tratamentos comportamentais tradicionais, tais como treinamento em habilidades sociais ou dessensibilização, por ser pautada nas oportunidades de mudanças profundas obtidas dentro das limitações de um relacionamento interpessoal íntimo e intenso. O transtorno obsessivo compulsivo é um transtorno de ansiedade caraterizado pela presença de obsessões e compulsões recorrentes e severas que causam sofrimento e prejuízo objetivo. Mesmo que à primeira vista não pareça um transtorno de ordem interpessoal, pretende-se ilustrar como a psicoterapia analítica funcional pode contribuir para seu tratamento. Isto é feito pela discussão de momentos nas sessões de uma cliente de 47 anos portadora de transtorno obsessivo compulsivo persistente desde a adolescência. Verifica-se que oportunidades de aprendizagem ao vivo podem ser identificadas no relacionamento terapeuta-cliente, e que há indícios para o efeito terapêutico dos mesmos.
\end{abstract}

Unitermos: Transtorno obsessivo-compulsivo. Psicoterapia analítico-funcional. Terapia comportamental.

\begin{abstract}
This article considers the possibilities of functional analytic psychotherapy in the treatment of obsessive compulsive disorder. Functional analytic psychotherapy is a form of behavioral psychotherapy, that differs from traditional behavioral treatments like social skills training or desensitization, because it focuses exclusively on the opportunities for profound change that occur within the confines of an intimate and intense interpersonal relationship. Obsessive Compulsive Disorder is an anxiety disorder characterized by repetitive and severe obsessions and compulsions that cause subjective suffering and objective losses. Although, at first sight, it is not an interpersonal problem, we will show how Functional Analytic Psychotherapy can contribute to its treatment. Turning-points are discussed in the relationship between a therapist and a 47 year-old client with treatment-resistant Obsessive Compulsive Disorder since early adolescence. In-vivo learning opportunities, as conceptualized by Functional Analytic Psychotherapy, are identified in the therapist-client relationship, and the reasons for the therapeutic effects are discussed.
\end{abstract}

Uniterms: Obsessive compulsive disorder. Functional analytic psychotherapy. Behavior therapy.

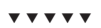

1 Consultório particular. Goiânia, GO, Brasil.

2 Pontifícia Universidade Católica de Goiás, Centro de Estudos e Pesquisa em Psicologia. R. 232, n.128, 30 andar, Setor Universitário, 74605-140, Goiânia, GO, Brasil. Correspondência para/Correspondence to: L. VANDENBERGHE. E-mail: <luc.m.vandenberghe@gmail.com>. 
O Transtorno Obsessivo Compulsivo (TOC) faz parte dos transtornos de ansiedade e se manifesta pela presença de obsessões e/ou compulsões recorrentes e severas que consomem mais de uma hora por dia do portador, causando sofrimento acentuado e prejuízo significativo. É característico o reconhecimento pelo indivíduo de que as obsessões ou compulsões são excessivas ou irracionais. Em cada cinquenta pessoas, uma pode apresentar TOC. Costuma aparecer no final da adolescência, em número semelhante para ambos os sexos, existindo casos de início mais precoce, principalmente no sexo masculino (American Psychiatric Association - APA, 2003).

Na patogênese pode haver contribuição dos fatores genéticos, da história de vida, do ambiente interpessoal imediato e da cultura na qual o indivíduo está inserido, observando que a última promove comportamentos obsessivos e compulsivos em diferentes momentos da vida - por exemplo, a atividade de estudar bem alguma matéria, tarefa em que se faz necessário o cuidado um tanto obsessivo, relendo e relembrando o assunto (Hounie et al., 2005).

Obsessões são ideias, pensamentos, impulsos ou imagens persistentes, vivenciados como intrusos e inadequados. O indivíduo sente que o conteúdo da obsessão é estranho, que não está dentro de seu controle e nem é o tipo de pensamento que ele esperaria ter. Reconhece que as obsessões são produtos de sua própria mente e não impostos pelo exterior. Exemplos comuns são: pensamentos repetidos acerca de contaminação; dúvidas repetidas; necessidade de organizar coisas em determinada ordem; medo de ter impulsos agressivos; imagens sexuais ou blasfêmias; preocupação exagerada com problemas em uma determinada área sem que estes ofereçam realmente perigo (APA, 2003).

Tomar consciência de vontades, imagens ou pensamentos involuntários que ocorrem e desaparecem espontaneamente é um fenômeno psicológico comum, e se a pessoa não der importância a eles, serão esquecidos (Wegner, 1989). Porém, quando se trata de pensamentos ou imagens inaceitáveis para a pessoa, ou que ameaçam a imagem de si, ela pode iniciar tentativas de suprimi-los e controlá-los. Isto pode ser o caso, por exemplo, de pensamentos incompatíveis com sua autoimagem ou que agridem seus valores centrais 546 (Ferrier \& Brewin, 2005). Outros elementos que favoreçam a transformação de pensamentos em obsessões são a sensação peculiar de não ter controle o suficiente e a tendência exagerada de monitorar, que foram detectadas em pessoas com TOC (Moulding, Doron, Kyrios \& Nedeljkovic, 2008).

Compulsões são atos repetidos que a pessoa se sente compelida a executar, visando prevenir ou reduzir o desconforto provocado pelas obsessões, ou para evitar alguma situação temida. Não têm conexão com um perigo real que deve ser evitado, ou então são claramente excessivos (APA, 2003). Exemplos são: lavar as mãos várias vezes para se tornar seguramente limpo; verificar várias vezes se trancou a porta para sentir-se seguro; contar até vinte para não cometer atos obscenos; guardar roupas velhas para que nunca falte o que vestir; tentar afastar pensamentos indesejáveis, substituindo-os por pensamentos contrários (Cordioli, 2004).

Existem, para oTOC, tratamentos empiricamente sustentados. Exemplos são: tratamentos comportamentais que visam extinguir as respostas condicionadas de ansiedade por procedimentos de exposição aos conteúdos que evocam as compulsões, sempre evitando que o comportamento compulsivo ocorra (Ito, 1996; Guimarães, 2001; Meyer \& Levy, 1973) e tratamentos cognitivos, que visam modificar as avaliações disfuncionais das imagens e dos pensamentos intrusos, como também a reestruturação das crenças irracionais que ajudam a manter o processo obsessivo-compulsivo (Clark, 2004; Fisher \& Wells, 2008; Rangé, 2003; St. Clare, Menzies \& Jones, 2008).

Em meta-análises de pesquisas sobre efeitos terapêuticos, a reestruturação cognitiva e a exposição com prevenção das respostas compulsivas mostraram uma eficácia comparável. A combinação das duas abordagens em um tratamento integrado nada acrescentou ao resultado (Rosa-Alcázar, Sánchez-Meca, Gómez-Conesa \& Marín-Martínez, 2008). Apesar da eficácia destes tratamentos, há um número importante de portadores de TOC que os rejeitam, ou que os aproveitam de forma limitada por causa de problemas que ocorrem no relacionamento terapeuta-cliente durante a aplicação das técnicas (Rachman, 2003). Tal observação justifica novas contribuições.

Como, à primeira vista, o TOC não é um problema de ordem interpessoal, não surpreende que os tratamentos mais tradicionais para este transtorno se 
concentrem no nível intrapessoal, onde se localizam as crenças e as respostas condicionadas subjacentes ao transtorno. Porém, neste artigo pretende-se ilustrar como princípios de uma psicoterapia interpessoal podem contribuir para o tratamento do TOC.

\section{O Modelo FAP}

A Psicoterapia Analítico-Funcional (FAP) (Kohlenberg \& Tsai, 2001) é um tipo de psicoterapia comportamental pautada nas oportunidades de mudanças profundas obtidas dentro das limitações de um relacionamento íntimo e intenso entre terapeuta e cliente. A vivência interpessoal profunda neste relacionamento oferece ao cliente oportunidades de aprendizagem ao vivo, que o ajudam a crescer e superar seus problemas no cotidiano. O cliente com fobia social sente-se criticado pelas interpretações do terapeuta e tem a oportunidade de aprender ao vivo como lidar com tal situação. A pessoa com personalidade dependente tem que aprender a lidar com os limites e desafios inerentes a um relacionamento próximo, pois é exposta, ao vivo, à intimidade do relacionamento com o terapeuta.

Oportunidades de aprendizagem ao vivo emergem no seio do relacionamento terapêutico quando o cliente emite comportamentos clinicamente relevantes em relação à pessoa do terapeuta. Estes são momentos em que o comportamento pode ser modelado diretamente a partir dos efeitos que têm sobre o relacionamento. Os comportamentos clinicamente relevantes do cliente que ocorrem durante a sessão são indicados pela sigla inglesa CRB (Clinically Relevant Behavior) e divididos em três categorias.

A primeira categoria inclui a ocorrência ao vivo dos problemas na interação com o terapeuta (CRB1): a terapia deve levar à diminuição destes comportamentos por meio de evocação e modelagem de modos alternativos de agir. A segunda categoria descreve os progressos do cliente (CRB2): são comportamentos com baixa ocorrência no início da terapia e que serão alvos de reforçamento por caracterizar melhoras ao vivo no relacionamento com o terapeuta. A terceira categoria inclui as interpretações que o próprio cliente faz dos seus comportamentos durante a interação com o terapeuta (CRB3): refere-se às falas do cliente sobre suas dificuldades, seus progressos e as suas causas (Kohlenberg \& Tsai, 2001).

As ações do terapeuta são: notar, evocar, responder e interpretar os comportamentos clinicamente relevantes do cliente. Estas atuações afetam os comportamentos do cliente através de três funções de estímulo:

Em primeiro lugar, o que o terapeuta faz pode funcionar como estímulo discriminativo, isto é, pode propiciar uma situação na qual é mais provável que ocorram certos comportamentos do cliente. Em segundo lugar, pode ter uma função eliciadora (evocando respostas emocionais, sensações, imagens ou pensamentos). Finalmente, as ações do terapeuta podem funcionar como reforçadores, isto é, consequências que aumentam a ocorrência de certo comportamento do cliente. Na FAP, o modo de ajudar o cliente é por meio destas diferentes funções das ações do terapeuta durante a sessão. Logo, o primeiro objetivo terapêutico é construir um relacionamento genuíno e intenso para que os problemas-alvo do cliente realmente ocorram dentro da sessão, para serem trabalhados ao vivo (Kohlenberg \& Tsai, 2001).

Os procedimentos de avaliação na FAP para gerar hipóteses clínicas e monitorar os progressos do cliente são os mesmos usados por terapeutas cognitivo-comportamentais: entrevistas, autorrelatos, questionários e registros. Durante todo o tratamento, a FAP utiliza técnicas vivenciais e exercícios de contato emocional, como também destaca a expressão honesta pelo terapeuta dos seus sentimentos em relação ao cliente, com o intuito de intensificar o relacionamento terapêutico e torná-lo um lugar de aprendizagem genuíno.

Suas estratégias de intervenção são colocadas na forma de regras para o terapeuta: observar atentamente o comportamento do cliente para intervir no momento certo; criar condições para evocar os comportamentos disfuncionais e as oportunidades de aprendizagem; reforçar os progressos do cliente quando ocorrem ao vivo em situação de consultório; observar quais os aspectos da pessoa do terapeuta ou quais ingredientes da sua maneira de estar junto ao cliente que são reforçadores para os comportamentos do cliente; compartilhar com o cliente suas interpretações de variáveis que afetam o seu comportamento (Tsai, Kohlenberg, Kanter \&Walz, 2008). 
Durante toda a sessão, o terapeuta procura detectar comportamentos que são relacionados ao transtorno para o qual o cliente procurou o tratamento. A pergunta-chave que guia o terapeuta é:"Isto está acontecendo agora"? Este questionamento é feito em relação à ocorrência de problemas ou das melhoras clínicas que podem se manifestar na forma com que o cliente lida com o terapeuta e com a situação terapêutica.

Como já apontado, os tratamentos empiricamente sustentados para o TOC não enfocam o relacionamento terapêutico como a FAP o faz, porém o objetivo deste estudo foi argumentar que o relacionamento terapêutico pode ser um instrumento alternativo ou complementar às técnicas que são atualmente aceitas. Em um estudo de caso, ilustrou-se a viabilidade deste modelo de psicoterapia, trazendo os princípios interpessoais da FAP para o tratamento do TOC.

\section{Método}

\section{Participante}

Senhora "A", portadora de TOC, 47 anos, casada, trabalha em um cargo comissionado de alta responsabilidade, é mãe de um filho vivo e sofreu também um aborto natural. Apresentou compulsões de puxar seus cabelos (tricotilomania), de contar quantos vãos havia na estante da sua sala, quantas portas tinha nos armários da sua cozinha e quantos orifícios havia no rosto das pessoas. Incomodava-se com números de coisas ímpares, pois isso causava a impressão de que "sobra alguém". Tinha a preocupação exagerada em exercer com perfeição todos os seus papéis: de filha, mãe, esposa, trabalhadora, e quando sentia que falhava, ficava aflita, ansiosa e se culpava. A tricotilomania a deixou quase calva na área onde puxava os cabelos, além de deixar o chão sujo, tornando-a preocupada em ser vista como uma pessoa que fazia "sujeira".

Nasceu no interior de outro estado, onde morou até os doze anos, quando veio com sua mãe para a capital onde atualmente mora. A mãe, costureira, quase se tornou freira, mas conheceu um viajante, casou-se com ele e, em pouco tempo, "A" nasceu. Quando ainda bebê, a mãe descobriu que o marido tinha outra família e se separou. Tinha três anos quando seu pai morreu. 548 Com sua mãe, morou por alguns anos em um barracão nos fundos da casa dos avós maternos adotivos. Várias vezes mãe e filha tiveram que se separar por motivo de trabalho da mãe. A sra. "A" relata esse fato como uma situação das mais dolorosas: "Preferiria que ela nem viesse para não termos que nos separar". Algumas vezes, "A" se mudava com a mãe para ajudá-la. Foi assim por anos, até que a mãe decidiu mudar para a capital de Goiás em busca de autonomia e liberdade.

Senhora "A" ganhou uma bolsa de estudos em uma escola renomada. Desde pequena já se mostrou muito responsável. Sempre se esforçou nos estudos e construiu um histórico escolar de boas notas. Formou-se em Direito e, logo na adolescência, começou a trabalhar. Foi manicure, professora e secretária executiva antes de ter acesso ao cargo comissionado de alto nível. Morou duas vezes nos Estados Unidos, em busca de salário melhor; assim conseguiu realizar o sonho de comprar uma casa própria para sua mãe. Na primeira vez que foi para o exterior era solteira e o namorado foi atrás. Tiveram um relacionamento sexual, que se tornou uma grande preocupação para a sra. "A", prevendo que para sua mãe era algo que não deveria acontecer antes do casamento religioso:"... me lembro de arrancar cabelos enquanto escrevia cartas para minha mãe tentando dizer sobre o que tinha acontecido".

\section{Procedimentos}

A cliente foi atendida em clínica particular, encaminhada por um psiquiatra, e indicada por um cliente da psicoterapeuta, primeira autora do trabalho. O caso foi discutido em supervisão e os resultados deste artigo foram organizados no decorrer das discussões entre a terapeuta e o supervisor, segundo autor deste texto. A casuística foi desenvolvida focando no que ocorreu entre a terapeuta e a cliente, para poder captar o processo interpessoal que a FAP propõe como elemento curativo central no tratamento. Mudanças no quadro clínico da cliente são descritos considerando o relacionamento da cliente com a terapeuta e a evolução deste relacionamento.

\section{Resultados}

O primeiro assunto interpessoal identificado foi a irritação da cliente com o filho, pelo modo como 
escovava os dentes. Nas palavras dela: "Ele não passa a escova sobre os dentes o tanto necessário". Ela observava o tempo que ele gastava na escovação, e caso achasse que tinha sido rápido, fazia-o repetir, além de ficar com semblante "assustador"e puxar todos os cabelos de uma vez. No trabalho também ficava impaciente com um colega lento e sem iniciativa na execução de tarefas. Não se permitia o mínimo de atraso ou o menor erro. Sentia necessidade excessiva de ficar atenta para antecipar e atender às necessidades do seu chefe e dos colegas.

Observa-se que o processo obsessivo-compulsivo interferiu diretamente no plano interpessoal. Logo alguns comportamentos disfuncionais no relacionamento com a terapeuta (CRB1) chamaram a atenção. A cliente chegava em torno de vinte minutos adiantada para as sessões, e desde o início expressava sua impaciência com a eficácia da terapia. A terapeuta buscou manter um bom vínculo, iniciando a sessão sempre no horário, mostrando cuidados com os sentimentos e preferências da cliente, aceitando os comportamentos disfuncionais como algo passível de mudança e sem intencionalidade.

A confiança que a cliente desenvolveu em relação à terapeuta foi considerada um progresso (CRB2) e acolhida pela última com uma escuta atenta a todas as informações que ela Ihe confiava. Assim, a terapeuta permitiu que, a partir da mudança de atitude da cliente no relacionamento com ela, desenvolvessem um relacionamento íntimo. Este, por sua vez, possibilitou à cliente expor detalhadamente situações traumáticas da infância, adolescência e fase adulta. Outra mudança importante ocorreu no seio do relacionamento quando a cliente, em contraste ao que tinha sido o seu estilo durante toda sua vida adulta, começou a conseguir escutar sem interrupção as falas da terapeuta e se interessar pelo que ela tinha a dizer.

Nas suas interações com a terapeuta, a cliente também se tornou gradualmente mais flexível quanto às suas próprias regras. Em um relacionamento entre pessoas que se dispõem a serem genuínas e a tentarem se entender mutuamente, não se é obrigado a fazer tudo como combinado ou esperado; assim, a cliente conseguiu, aos poucos, transgredir suas regras rígidas. Com a preocupação de não punir as primeiras brechas nesta rigidez, a terapeuta, ao contrário do que tinha sido combinado, não cobrava a sessão desmarcada na última hora e acolhia a cliente quando cometia atos considerados por ela - a cliente - irresponsáveis.

No decorrer do processo terapêutico, a terapeuta observou que as características dela que se caracterizavam como reforçadoras para os progressos da cliente eram: sua assiduidade, sua maneira de acolher e sua disponibilidade emocional. É importante enfatizar que estas reações da terapeuta à pessoa da cliente encaixam-se em categorias de reforçadores naturais aos quais a cliente, por meio de suas novas atitudes, também teve acesso no seu cotidiano fora da sessão. Isto significa que a sra. "A" podia, com seu comportamento menos condenatório, mais espontâneo e aberto para com os outros, evocar nas pessoas com quem interagia as mesmas atitudes que evocou na pessoa da terapeuta.

As mudanças que ocorreram no relacionamento com a terapeuta gradualmente transpareceram no cotidiano: a cliente começou a agir de maneira menos tensa e preocupada, passando a avaliar o comportamento dos outros de forma mais positiva, principalmente os que se comportavam mais lentamente, sem rigidez e sem preocupação com a perfeição.

Procurou-se compreender os comportamentos da cliente por meio de interpretações que foram construídas pela terapeuta e pela cliente em conjunto. Relatos da cliente de que puxava seus cabelos quando tinha que dar cola de prova para uma colega, ou quando quebrava alguma outra regra, ajudaram nesta tarefa. Comportamentos ao vivo durante a sessão, como se agitar na poltrona ou elevar as mãos na cabeça quando falava destes assuntos, permitiam relacionar os sintomas com sentimentos de culpa e vivências de castigos. A obsessão "algo que está em número ímpar significa que alguém fica sobrando" foi relacionada a várias situações traumáticas da infância nas quais foi excluída - por exemplo, vivenciou a situação de ver uma prima da sua idade ser arrumada para tirar uma foto; ela ficou perto da prima, com vontade de participar, e quando seu rosto saiu junto na fotografia foi punida.

Em um determinado período da terapia, do sexto ao $15^{\circ}$ mês, o relacionamento permitiu que a cliente expressasse e processasse uma sequência de situações estressantes e de crises que invadiam seu cotidiano. A descoberta de câncer, a cirurgia de retirada total da mama e o início do tratamento de quimioterapia leva- 
ram a uma mudança brusca de temas nas sessões, sendo abordados principalmente as orientações médicas, as dúvidas da cliente, sua perspectiva para o futuro e a preparação para o tratamento. A morte de um familiar com o qual tinha vínculo próximo foi o contexto para que a cliente entrasse em contato com suas crenças de morte e a vivência do luto.

O falecimento da mãe de "A" levou a um novo contato intenso com sentimentos de culpa e cobrança. A crença de que não deu toda a atenção que deveria ter dado à sua mãe e pensamentos de que poderia perder também o marido e o filho a qualquer momento porque "a morte está cada vez mais perto das pessoas mais importantes" foram discutidos nas sessões. Neste período, a terapeuta observou que a cliente tentou evitar a expressão de sentimentos de raiva, medo e dor, falando de situações dolorosas sorrindo e brincando, além de desviar seus pensamentos para como poderia ajudar outras pessoas. Evidenciou-se a crença de que assim poderia evitar o sofrimento de outros.

Foi considerado um CRB1 quando a cliente relatava situações sofridas sem demonstrar emoções para poupar a terapeuta de sofrer também, assim como fez com seus familiares e amigos. Relativo a este problema, um progresso (CRB2) foi identificado quando a cliente conseguia expressar o que realmente sentia, por meio de uma escolha espontânea de palavras, choro e linguagem corporal. A terapeuta reagiu sentando-se mais próximo da cliente e deu maior tempo de sessão, mostrando o quanto a expressão de suas emoções era importante para seu vínculo e para o progresso do trabalho.

Um CRB3 ocorreu quando a cliente chegou a interpretar que a camuflagem do seu sofrimento era uma forma de responsabilidade excessiva para com a terapeuta, como também era o caso no seu cotidiano, onde se impunha a mesma limitação, como se ela tivesse o poder de evitar que os outros sofressem.

No terceiro mês de terapia, a cliente já tinha parado de puxar os cabelos, mas durante o trabalho intensivo com a vivência de sentimentos de culpa tinha recaídas, ainda que com menor frequência e intensidade. Os comportamentos de contar números de portas, vãos e orifícios desapareceram depois de ter trabalhado o sentimento de que números ímpares significavam que "sobrava alguém". Também se concentrava menos na solução dos problemas dos outros e com exigências exageradas. Passou a se cuidar mais, praticando exercícios físicos e lazer. Mostrou mais vaidade com sua aparência e tornou mais intensos os relacionamentos com os familiares e pessoas da sua confiança.

Em alguns contatos feitos até sete meses depois do encerramento do tratamento (que durou ao todo dezoito meses), não houve retorno dos padrões obsessivo-compulsivos. Seu trabalho tinha se tornado uma atividade que oferecia prazer e muito menos sofrimento. Ela deixou de chegar muito cedo ao trabalho, e até algumas vezes se permitiu chegar atrasada. Passou a se sentir muito melhor com as pessoas, reconhecendo que elas próprias são capazes de resolver muitos dos seus problemas.

\section{Discussão}

No relato acima foi descrita uma abordagem interpessoal para um quadro obsessivo-compulsivo. 0 percurso deste tratamento ilustra alguns elementos-chave destacados da literatura concernentes ao TOC, mostrando que podem ser abordados a partir de um enfoque interpessoal. Trata-se de aspectos do TOC para os quais técnicas específicas existem, mas que, neste caso, foram abordados ao vivo na sessão, a partir da própria vivência do relacionamento terapêutico.

Reações excessivas à percepção abstrata de que algo parece errado (Coles, Frost, Heimberg \& Rheaume, 2003) que, nos tratamentos comportamentais e cognitivos, geralmente são foco de técnicas específicas, foram trabalhados naturalmente, enquanto a cliente aprendia a lidar com sentimentos de imperfeição e aceitação de inadequações no seu relacionamento com a terapeuta. A insegurança insaciável e a necessidade de sempre vigiar para evitar problemas (Szechtman \& Woody, 2004) melhorou da mesma forma, enquanto a cliente aprendeu a aceitar a insegurança em um relacionamento que era emocionalmente nutritivo sem que a outra pessoa (a terapeuta) estivesse por isso controlável ou previsível.

Enquanto a literatura propõe métodos explícitos para reduzir a supervalorização de perigo idealizado, que tão frequentemente se encontra no transtorno obsessivo-compulsivo (St. Clare et al., 2008), a cliente se arriscou em um relacionamento diferente, profundo e 
intenso, sem informação confiável de como a outra pessoa (a terapeuta) iria reagir. Aceitou a quebra de regras e tomou o risco de transgredir também. Assim, aprendeu a crescer sem se subjugar aos seus medos.

A responsabilidade exagerada, apontada por Rachman (2003) como aspecto importante a ser trabaIhado no tratamento comportamental do TOC, estava presente com destaque na vida da cliente e na sua maneira de encarar o processo terapêutico. Neste tratamento, a terapeuta acolheu quebras de regras pela cliente, o que significava um progresso clínico ao vivo. Assim providenciou um relacionamento interpessoal que permitiu à cliente ser flexível e espontânea, duas atitudes que logo transformariam seus relacionamentos cotidianos com muitas pessoas.

A literatura aponta para a presença, em certos clientes com TOC, de uma dificuldade em expressar emoções, problema às vezes atribuído a um traço de alexitimia subjacente ou uma tendência de agressividade passiva implícita na desconsideração para com as preferências dos outros (Hand, 1992). No trabalho aqui descrito, entendeu-se que a expressão emocional tinha sido enfraquecida durante toda a infância e juventude da cliente, que precisou desconsiderar muitas das suas necessidades emocionais, mantendo-se em segundo plano e se adequando às regras dos outros, enquanto estava morando de favor com os pais adotivos da mãe, enquanto enfrentou separações repetitivas e construiu seu caminho, com grande responsabilidade e sacrifício, contando apenas consigo mesma. No seio do relacionamento interpessoal entre terapeuta e cliente houve um espaço favorável ao desenvolvimento da expressão genuína de si e da colocação de necessidades emocionais.

A cliente aprendeu a ver a outra pessoa (a terapeuta) como alguém que tinha tanto suas boas intenções quanto suas imperfeições e falhas, ou seja, mais do que alguém que deveria ser eficaz e avaliado de acordo com normas de produtividade. Esta habilidade de aceitar as particularidades da outra pessoa parece ter contribuído em medida importante para que a Sra. A. abrisse mão da sua responsabilidade excessiva e começasse a aceitar tanto a si mesma quanto às outras pessoas independentemente da adequação delas a regras abstratas.

\section{Considerações Finais}

Estes resultados sugerem que é possível tratar o TOC mediante relacionamento terapêutico. Não foi intenção neste trabalho propor o abandono dos tratamentos comportamentais e cognitivos atuais para o TOC, mas tornar a terapia mais profunda, através do aproveitamento terapêutico das oportunidades de aprendizagem ao vivo que ocorrem no seio deste relacionamento interpessoal. A FAP pode se tornar uma maneira de intensificar o tratamento deste transtorno ou até oferecer uma alternativa para clientes que se mostram resistentes aos tratamentos empiricamente sustentados.

Futuras pesquisas experimentais poderiam comparar os efeitos de tratamentos já empiricamente avaliados com e sem a adição de FAP, para averiguar a contribuição objetiva desta abordagem para o tratamento doTOC.

\section{Referências}

American Psychiatric Association. (2003). DSM-IV Manual diagnóstico e estatístico dos transtornos mentais. Porto Alegre: Artes Médicas.

Clark, D. (2004). Cognitive-behavior therapy for OCD. New York: Guilford.

Cordioli, A. V. (2004). Vencendo o transtorno obsessivo-compulsivo: manual da terapia congnitivo-comportamental para pacientes e terapeutas. Porto Alegre: Artes Médicas.

Coles, M. E., Frost, R. O., Heimberg, R. G., \& Rheaume, J. (2003). Not just right experiences: perfectionism, obsessive-compulsive features and general psychopathology. Behaviour Research \& Therapy, 41 (7), 681-700.

Ferrier, S., \& Brewin, C. R. (2005). Feared identity and obsessive-compulsive disorder. Behaviour Research and Therapy, 43 (9), 1363-1371.

Fisher, P. L., \& Wells, A. (2008). Meta-cognitive therapy for obsessive-compulsive disorder: a case series. Journal of Behavior Therapy and Experimental Psychiatry, 39 (2), 117-132.

Guimarães, S. (2001). Exposição e prevenção de respostas no tratamento do transtorno obsessivo-compulsivo. In M. L. Marinho \& V. E. Caballo (Orgs.), Psicologia clínica e da saúde (pp.177-196). Londrina: UEL.

Hand, I. (1992). Verhaltenstherapie der Zwangsstörungen. In I. Hand, W.K. Goodman \& U. Evers (Orgs.), Zwangsstörungen:neueForschungsergebnisse (pp.89-124). Berlin: Springer Verlag. 
Hounie, A G., Lopes A. C., Labate C., Belotto C., Mathiis M. E., \& Borcato S. (2005). Transtorno obsessivo-compulsivo. São Paulo: Protoc.

Ito, L. M. (1996). Abordagem comportamental do transtorno obsessivo-compulsivo. In E C. Miguel Filho (Org.), Transtornos de espectro obsessivo-compulsivo (pp.98-105). Rio de Janeiro: Guanabara Koogan.

Kohlenberg, R. J., \& Tsai, M. (2001). Psicoterapia analítico funcional: criando relações terapêuticas intensas e curativas. Santo André: ESETec.

Meyer, V., \& Levy, R. (1973). Modification of behavior in obsessive-compulsive disorders. In H. E. Adams \& P. Unikel (Orgs.), Issues and trends in behavior therapy (pp. 77-136). Springfield: Charles Thomas.

Moulding, R., Doron, G., Kyrios, M., \& Nedeljkovic, M. (2008). Desire for control, sense of control and obsessivecompulsive checking: an extention to clinical samples. Journal of Anxiety Disorders, 22 (8), 1472-1479.

Rachman, J. S. (2003). The treatment of obsessions. Oxford: Oxford University Press.

Rangé, B. P. (2003). Transtorno obsessivo-compulsivo. In R. M. Caminha, R. Wainer, M. S. Oliveira \& N. Piccoloto (Orgs.), Psicoterapias cognitivo-comportamentais: teoria e prática (pp.145-153). São Paulo: Casa do Psicólogo.
Rosa-Alcázar, A. I., Sánchez-Meca, J., Gómez-Conesa, A., \& Marín-Martínez, F. (2008). Psychological treatment of obsessive-compulsive disorder: a meta-analysis. Clinical Psychology Review, 28 (8), 1310-1325.

St.Clare, T., Menzies, R. G., \& Jones, M. K. (2008). Danger ideation therapy (DIRT) for obsessive compulsive washers: a comprehensive guide to treatment. Bowen Hills: Australian Academic Press.

Szechtman, H., \& Woody, E. (2004). Obsessive-compulsive disorder as a disturbance of security motivation. Psychological Review, 111, 111-127.

Tsai, M., Kohlenberg, R. J., Kanter, J. W., \& Waltz, J. (2008). Therapeutic technique: the five rules. In M. Tsai, R. J. Kohlenberg, J. W. Kanter, B. Kohlenberg, W. C. Follette \& G. M. Callaghan (Orgs.), A guide to functional analytic psychotherapy: awareness, courage, love and behaviorism (pp.61-102). New York: Springer.

Wegner, D. M. (1989). White bears and other unwanted thoughts. Supression, obsession and the psychology of mental control. New York: Guilford.

Recebido em: 14/12/2007

Versão final reapresentada em: 16/2/2009

Aprovado em: 13/3/2009 